\title{
Assessment of the possibility of using flocculation to improve properties of ultrafiltration membranes used in the purification of swimming pool water system washings
}

\author{
Edyta Laskawiec $^{1,{ }^{*}}$, Mariusz Dudziak ${ }^{1}$, and Joanna Wyczarska-Kokot ${ }^{1}$ \\ ${ }^{1}$ Institute of Water and Wastewater Engineering, Silesian University of Technology, Konarskiego 18, \\ 44-100 Gliwice, Poland
}

\begin{abstract}
The paper presents the possibility of using an in-line mode flocculation-ultrafiltration system for the purification of backwash water from flushing the beds of pressure filters used in the indoor swimming pool water treatment circulation. The effect of flocculation operational conditions (the flocculant dose in the range from 16 to $240 \mathrm{mg} / \mathrm{dm}^{3}$ and the process temperature of $8-30^{\circ} \mathrm{C}$ ) on the transport-separation properties of ultrafiltration membranes has been examined. To establish the effectiveness of the conducted processes, the contaminant retention coefficients, among others, were determined (based on the measurements of turbidity and UV254 ultraviolet absorbance). A significant influence of the flocculation process operational parameters on the performance of ultrafiltration was noted. With increasing flocculant dose, the efficiency of contaminant removal in the ultrafiltration process increased simultaneously. Moreover, the change in the temperature conditions of the flocculation process had a fundamental effect on the transport properties of the ultrafiltration membranes. The most advantageous temperature for conducting the processes was considered to be $21^{\circ} \mathrm{C}$. Under those conditions, all flocculant doses contributed to a significant improvement in the transport properties of the ultrafiltration membranes. High values of the contamination retention coefficients and the permeate volumetric flux were obtained already at a flocculant dose of 80,160 and $240 \mathrm{mg} / \mathrm{dm}^{3}$.
\end{abstract}

\section{Introduction}

The filtration process constitutes a basic element of water treatment systems in swimming pool facilities. During the flow of water through the bed, contaminant particles are retained in pores, which results in an increase in hydraulic losses. To prevent the bed breakthrough phenomenon and the contaminants passing on to the treated water, it is necessary to conduct bed washing with the reverse water and/or air stream at the

*Corresponding author: edyta.laskawiec@polsl.pl 
appropriate frequency. In order to conduct the process in a correct manner, it is necessary to use $4-6 \mathrm{~m}^{3}$ of water per each $\mathrm{m}^{2}$, as a result of which a waste water stream, called backwash water, is formed. In the facility examined within the present study, the swimming pool circulation includes two $1800 \mathrm{~mm}$-diameter filters which are washed every 48 hours, which generates a monthly water consumption from 245 to $365 \mathrm{~m}^{3}$. The backwash water is discharged directly to the sewage system, which involves both wastage and high water drawing and waste water discharge costs [1-5]. Tests on the use of membrane pressure ultrafiltration for backwash water purification are being presently conducted [7]. It has been determined, though, that the chemical compounds and suspension present in the backwash water intensify membrane pore clogging. Hence, methods for supporting these processes are being searched for, which will increase the magnitude of the permeate volumetric flux, while maintaining the high separation abilities of the membranes.

The present investigation comprised the exploration of the possibility of using flocculation as an operation aiding the membrane ultrafiltration process. The purification system operated in an in-line batch mode, whereby the flocculant was introduced directly to the filtration cell. During the tests, an attempt was made to establish the operational parameters of the flocculation process (the flocculant dose and the process temperature), which contribute to an improvement in membrane transport-separation conditions, such as the permeate volumetric flow and the contaminant retention coefficient.

\section{Materials and test methods}

\subsection{Characterization of backwash water tested}

Backwash water used in the tests was a stream of waste water from washing multilayered pressure filters constituting an element of an indoor swimming pool water treatment system. The facility under investigation is characterized by a high load with bathers, being the place of swimming lessons taken by children and young people of nearby schools and a form of recreation for adult city dwellers. A mixture of backwash water originating from the swimming pool circulation and a hot tub was used in the tests. The basic physicochemical parameters of the backwash water are given in Table 1.

Table 1. The physicochemical parameters of the backwash water.

\begin{tabular}{|c|c|c|}
\hline Parameter & Unit & Value \\
\hline Reaction $(\mathrm{pH})$ & - & 7.14 \\
\hline Conductivity $(\mathrm{PWC})$ & $\mu \mathrm{S} / \mathrm{cm}$ & 960.00 \\
\hline Turbidity & $\mathrm{NTU}$ & 26.60 \\
\hline Colour $\left(\mathrm{C}_{\mathrm{Pt}}\right)$ & $\mathrm{mgPt}-\mathrm{Co} / 1$ & 306.00 \\
\hline $\begin{array}{c}\text { Ultraviolet absorbance } \\
(\mathrm{UV} 254)\end{array}$ & $\mathrm{m}^{-1}$ & 23.50 \\
\hline
\end{tabular}

\subsection{Analytical procedures}

The quality assessment of the test backwash water before and after the purification processes was made based on selected physicochemical properties. The measurement of the conductivity $(\mathrm{PWC})$ and reaction $(\mathrm{pH})$ of tested samples was done with an inoLab ${ }^{\circledR} 740$ 
multi-parameter meter (WTW, Measuring and Analytical Technical Equipment). The ultraviolet absorbance at a wavelength of $254 \mathrm{~nm}$ was measured using a UV VIS Cecil 1000 supplied by Analytik Jena AG, with a cuvette optical pathlength of $1 \mathrm{~cm}$. The $\mathrm{UV}_{254}$ value was determined based on the measurement method presented by US EPA [6], and the final analysis result was expressed in $\mathrm{m}^{-1}$. For the determination of the turbidity of samples, an EUTECH Instruments Turbidimeter, Model TN-100, was employed. The measurement of the colour was performed using a UV VIS Spectroquant ${ }^{\circledR}$ Pharo 300 spectrophotometer (Merck) using a wavelength of $340 \mathrm{~nm}$.

\subsection{Operational parameters of the purification process in the in-line flocculation-ultrafiltration system}

For carrying out backwash water flocculation, a product under the commercial name of Flockfix (supplied by Chemoform AG), being a solution of dialuminium pentahydroxychloride, commonly used in swimming pool facilities, was used. The colourless liquid was characterized by density at a level of $1.024 \mathrm{~g} / \mathrm{cm}^{3}$ and active substance concentration in the range from $2.5 \%$ to $10 \%$, as stated by the manufacturer. To assess the effectiveness of a single flocculation operation within preliminary testing, typical beaker tests were performed, which included: A one-minute fast mixing process (at $250 \mathrm{rpm}$ ), followed by 25 minutes' flocculation at a mixer rotational speed of $20 \mathrm{rpm}$ conducted in a four-stand laboratory coagulator (Velp Scientifica). The process was conducted at different backwash water temperatures, namely 8,21 and $30^{\circ} \mathrm{C}$, for each of the assumed doses. The temperature conditions were assumed based the considered backwash water storage variants - in an external tank in spring-summer conditions or in a decanter located in the swimming pool understructure $\left(21^{\circ} \mathrm{C}\right)$, in an external tank in winter conditions $\left(8^{\circ} \mathrm{C}\right)$ and in a flow-through tank with the filtration process being conducted directly after washing the filters $\left(30^{\circ} \mathrm{C}\right)$. Directly after the process of flocculation started the membrane filtration.

The tests of the in-line mode flocculation-membrane ultrafiltration process involved the determination of the relationship between the conditions of the conducted flocculation process and the transport-separation properties of the ultrafiltration membranes in a wide range of flocculant doses $\left(16,80,160,240 \mathrm{mg} / \mathrm{dm}^{3}\right)$ and the above-mentioned temperatures. In this process, the flocculant was fed directly to the membrane cell which, at the same time, played the role of a reaction chamber. Filtration was started after the fast mixing and flocculation processes.

For membrane filtration, an ultrafiltration membrane with the symbol MW supplied by GE Osmonics Inc. (USA), whose characteristics, along with the operational parameters of the ultrafiltration process, are given in Table 2 .

Table 2. Characteristics of the ultrafiltration membrane and the operational parameters of the process.

\begin{tabular}{|c|c|c|c|c|}
\hline $\begin{array}{c}\text { Membrane-forming } \\
\text { material }\end{array}$ & $\begin{array}{c}\text { Cut-off molar } \\
\text { mass, Da }\end{array}$ & $\begin{array}{c}\text { Membrane } \\
\text { active filtration } \\
\text { surface area, } \\
\mathbf{m}^{2}\end{array}$ & $\begin{array}{c}\text { Trans- } \\
\text { membrane } \\
\text { process } \\
\text { pressure, } \\
\mathbf{M P a}\end{array}$ & $\begin{array}{c}\text { Deionized water } \\
\text { permeate } \\
\text { volumetric flux, } \\
\mathbf{J w} \cdot \mathbf{1 0}^{-5}, \mathbf{m}^{\mathbf{3}} / \mathbf{m}^{2} \mathbf{s}\end{array}$ \\
\hline Polyacrylonitrile & 50000 & 0.00385 & 0.2 & 2.60 \\
\hline
\end{tabular}

The membrane was placed in a $380 \mathrm{~cm}^{3}$ steel filtration cell equipped with a magnetic stirrer. Before starting filtration, the new membrane was conditioned by filtrating deionized water until the permeate volumetric flux stabilized. The proper filtration process was 
conducted in a dead-end unidirectional filtration system until the $50 \%$ of the feed volume was received. At the same time, selected physicochemical parameters were verified in successively received $25 \mathrm{~cm}^{3}$-volume permeates and the magnitudes of the permeate volumetric flux were determined. Six measurements were taken at each cycle. After each cycle comprising the filtration of the post-flocculation solution under specified conditions, the membrane was washed with deionized water. This was aimed at removing any residues of the suspension deposited on the membrane surface. After that stage, the permeate volumetric flux was determined again for deionized water, which was used for determining the degree of membrane pore clogging.

\subsection{Parameters of the assessment of the ultrafiltration membrane transport- separation properties}

The assessment of the transport properties of membranes in filtration processes was made based on the volumetric flux of deionized water, $J_{v}$ (during conditioning the membrane with water), and the permeate, $J_{\mathrm{w}}$ (the proper filtration process), from the following equation:

$$
J_{w}=\frac{v}{F \cdot t}, \frac{m^{3}}{m^{2} \cdot s}
$$

where: V - volume of water of permeate, $\mathrm{m}^{3} ; \mathrm{F}$ - membrane active surface area, $\mathrm{m}^{2}$; $\mathrm{t}$ - filtration time, $\mathrm{s}$.

To assess the separation properties of membranes, the retention (R) was determined, whose value was determined based on the reduction in the values of respective contamination indices:

$$
R=\left(1-\frac{c_{p}}{c_{n}}\right), \%
$$

where: $c_{p}$ - concentration (index value) of contaminants in the permeate stream, $c_{n}$ concentration (index value) of contaminants in the feed.

The intensity of the reduction in membrane transport abilities (membrane pore clogging degree) was determined by calculating the value of the relative permeate volumetric flux:

$$
\alpha=\frac{J_{w}}{J_{v}}
$$

where: $J_{w}$ - value of the permeate volumetric flux at the sixth measurement point, $\mathrm{m}^{3} / \mathrm{m}^{2} \cdot \mathrm{s}$; $\mathrm{J}_{\mathrm{v}}-$ value of the deionized water volumetric flux, $\mathrm{m}^{3} / \mathrm{m}^{2} \cdot \mathrm{s}$.

\section{Test results}

Figure 1 shows the transport-separation characteristics of membranes for the processes of filtering, respectively, raw backwash water and backwash water subjected to flocculation at a temperature of $21^{\circ} \mathrm{C}$ with a flocculant dose of 6,160 and $240 \mathrm{mg} / \mathrm{dm}^{3}$. A significant influence of the flocculation process operational parameters on the performance of ultrafiltration was noted. During the filtration of raw backwash water (with no flocculant), the average relative permeate volumetric flux was 0.74 , which indicates a reduction in 
membrane efficiency by $26 \%$. Whereas, the values of the contaminant retention coefficients, as determined by the measurement of turbidity or UV254 ultraviolet absorbance, amounted to approx. 98\% and approx. 97\%, respectively. The obtained results confirm the high effectiveness of the ultrafiltration process in removing the suspension present in the backwash water tested and part of the contaminants determined by the UV254 ultraviolet absorbance measurements. These results also document the fact of the occurrence of the membrane pore clogging phenomenon that reduces the values of the permeate volumetric flux. In turn, with increasing flocculant dose, a distinct increase in contaminant retention degree value was observed. By contrast, the relative permeate volumetric flux decreased in those conditions. With the increase in flocculant dose from 16 to $240 \mathrm{mg} / \mathrm{dm}^{3}$, the average relative permeability of the membrane decreased from 1.26 to 0.97 . Under the temperature conditions tested, all of the applied flocculant doses increased the membrane transport conditions. Moreover, already a flocculant dose of $80 \mathrm{mg} / \mathrm{dm}^{3}$ allowed higher contaminant retention coefficient values to be obtained, compared to the results of raw backwash water filtration.

a)

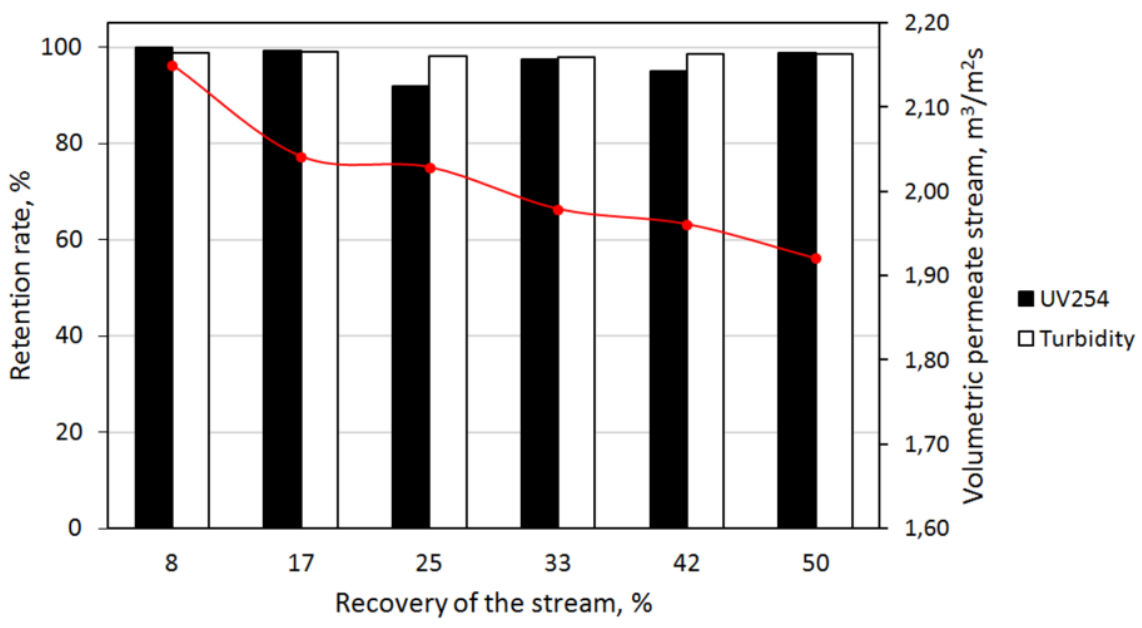

b)

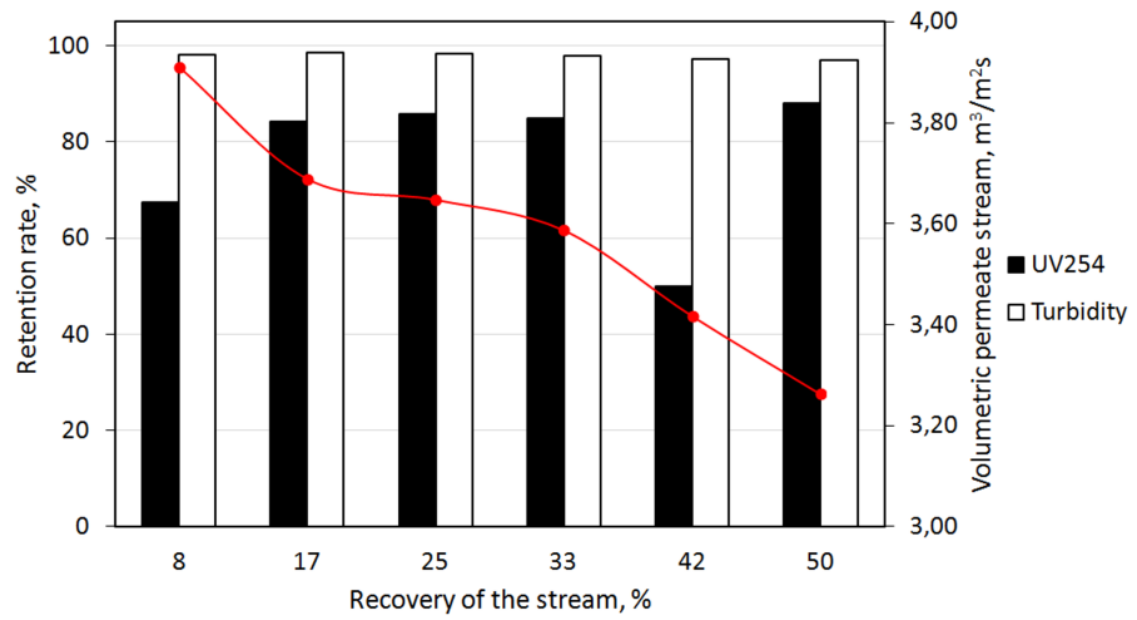


c)

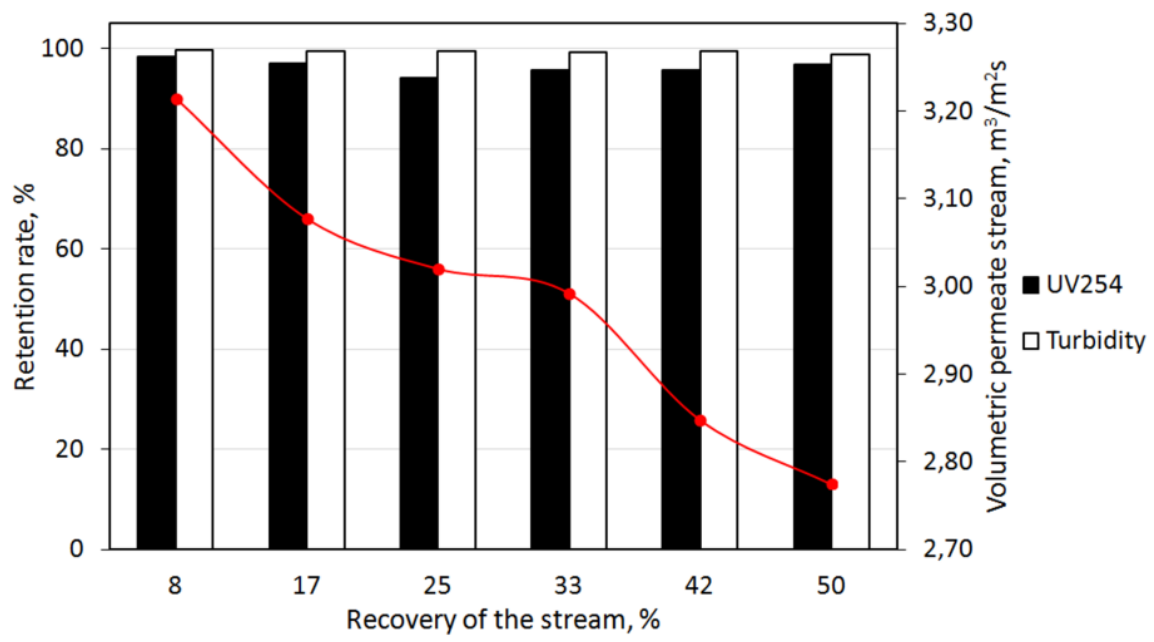

d)

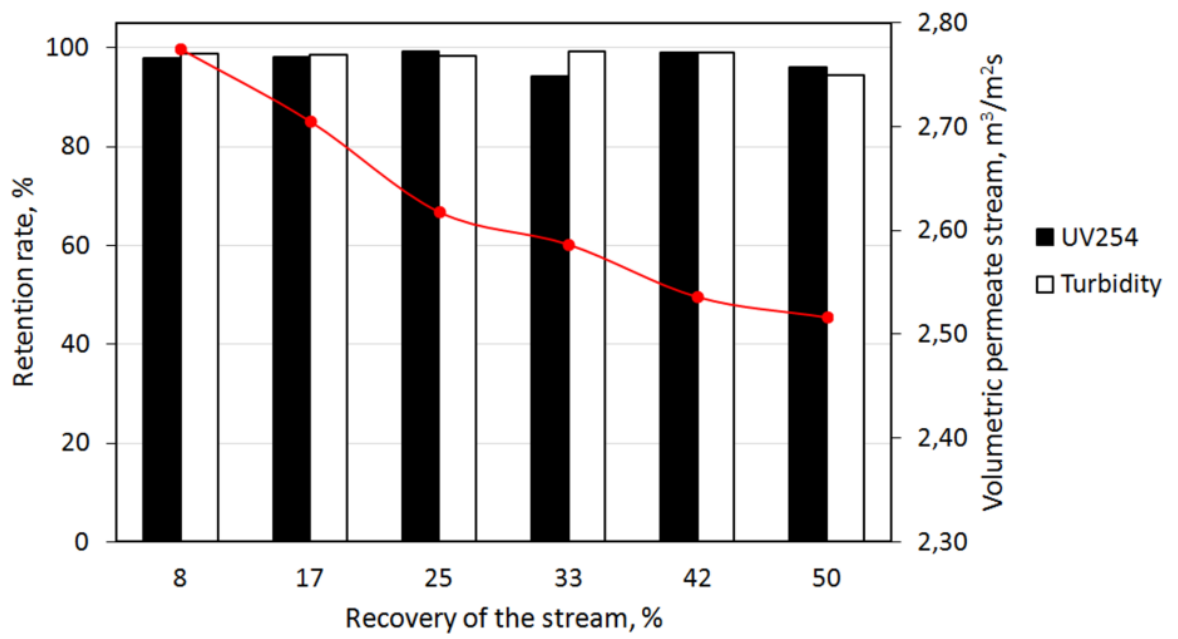

Fig. 1. The transport and separation properties of the ultrafiltration membrane during the filtration of a) raw backwash water, and backwash water with a flocculant dose of: b) $16 \mathrm{mg} / \mathrm{dm}^{3}$ c) $160 \mathrm{mg} / \mathrm{dm}^{3}$ d) $240 \mathrm{mg} / \mathrm{dm}^{3}$, at a temperature of $21^{\circ} \mathrm{C}$.

Figure 2 shows a comparison of the transport-separation abilities of the membrane for processes conducted at a temperature of 8 and $30^{\circ} \mathrm{C}$ with a flocculant dose of $16 \mathrm{mg} / \mathrm{dm}^{3}$. Also for backwash water that underwent flocculation at temperatures of 8 and $30^{\circ} \mathrm{C}$, an increase in the separation abilities of the ultrafiltration membrane was observed with increasing flocculant dose. Whereas, the values obtained at lower flocculant doses were higher for flocculation-ultrafiltration conducted at a lower temperature.

The change in the temperature conditions of the flocculation process had a fundamental effect on the transport properties of the ultrafiltration membrane. At a temperature of $8^{\circ} \mathrm{C}$, an increase in the average relative permeate volumetric flux was noted only in the case of the filtration of backwash water with a flocculant dose of $160 \mathrm{mg} / \mathrm{dm}^{3}(\alpha=0.76)$. In the remaining cases, the relative permeate volumetric flux value $\alpha$ was lower than that for the purification of raw backwash water. Furthermore, in spite of the high values of contamination retention coefficients for the flocculation-ultrafiltration process conducted at 
$30^{\circ} \mathrm{C}$ with a flocculant dose of 160 and $240 \mathrm{mg} / \mathrm{dm}^{3}$, much lower values of permeate volumetric fluxes were obtained ( $\alpha$ at a level of approx. 0.50 ).

a)

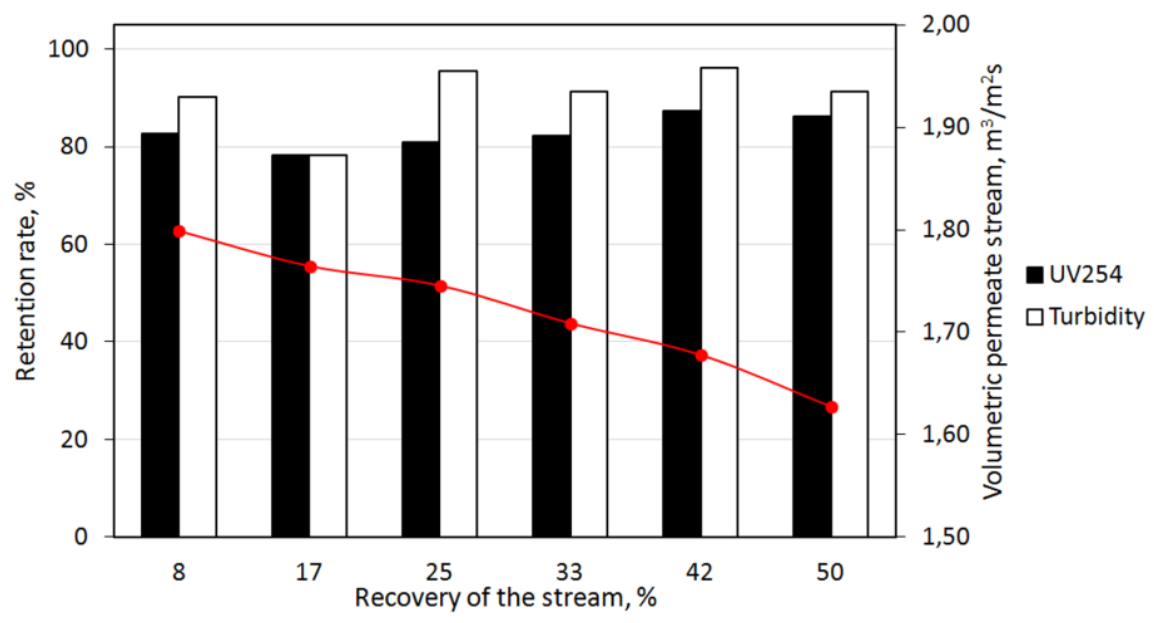

b)

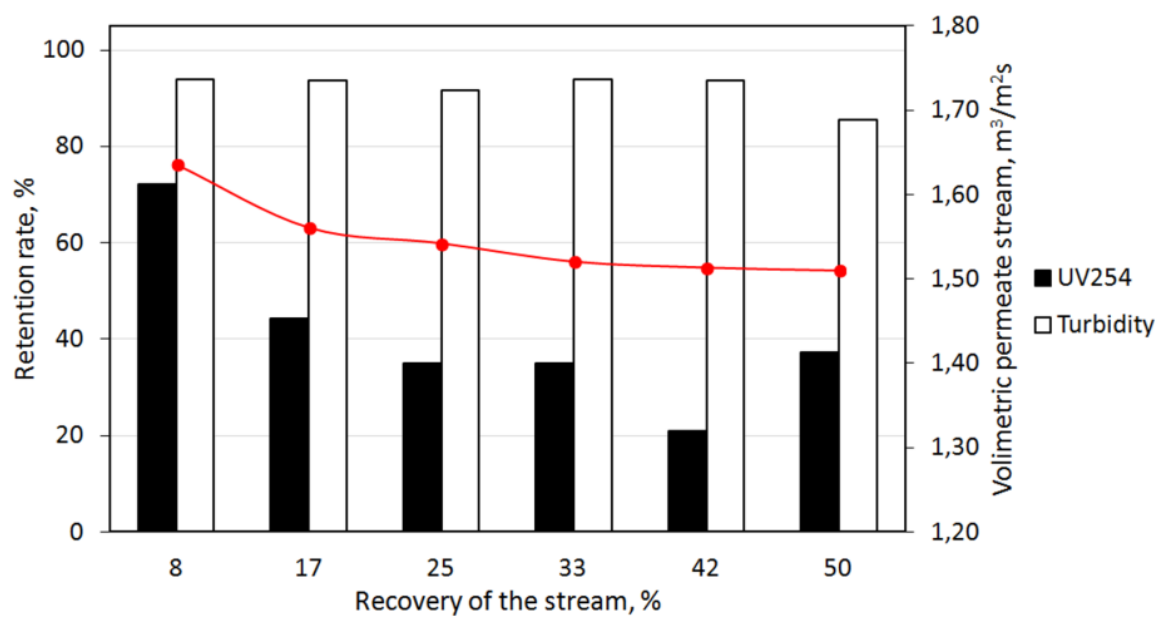

Fig. 2. The transport and separation properties of the ultrafiltration membrane - backwash water after flocculation with a flocculant dose of $16 \mathrm{mg} / \mathrm{dm}^{3}$ at a process temperature of 8 (Fig. 2a) and $30^{\circ} \mathrm{C}$ (Fig 2b), respectively.

Among the presented backwash water purification systems, the most advantageous transport-separation conditions were shown by the variant with the flocculation process conducted at $21^{\circ} \mathrm{C}$ and with a flocculant dose of $80 \mathrm{mg} / \mathrm{dm}^{3}$. Fig. 3 compares the effects of using the above-mentioned dose for three temperature variants. 


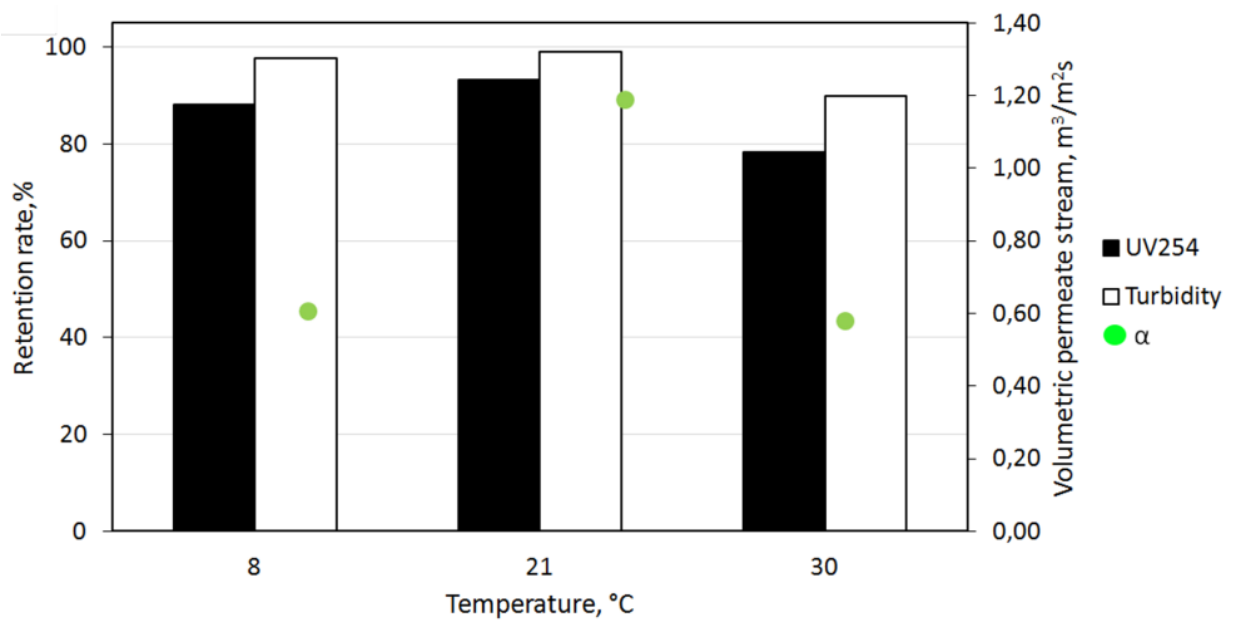

Fig. 3. The transport and separation properties of the ultrafiltration membrane - backwash water with $80 \mathrm{mg} / \mathrm{dm}^{3}$ flocculant doses.

\section{Summary}

The investigation has confirmed the high effectiveness of pressure membrane systems in removing contaminations from backwash water coming from the swimming pool water circulation. The use of hybrid (flocculation-ultrafiltration) processes could improves the transport-separation properties of ultrafiltration membranes. The flocculation process has a particular importance in this case, as it increases the degree of removal of organic substances from the waste stream. It should be borne in mind, however, that the flocculant dose depend on the waste stream composition and concentration and on the nature of backwash water obtained in a given facility, including its physicochemical parameters. It is proposed that tests in a purification system with capillary immersed membranes should be carried out within further investigations on this subject.

\section{References}

1. P. Wiercik, M. Domańska, Sci. Rev. Eng. Env. Sci., 54, 333-343 (2011)

2. I. Zimoch, Ochr Sr, 4, 17-22 (2013)

3. M. Meggeneder, J. Łomotowski, P. Wiercik, Ochr Sr, 4, 53-56 (2011)

4. M. Leszczyńska, M. M. Sozański, Environ, 40, 575-585 (2009)

5. J. Wyczarska-Kokot, Proceedings of ECOpole, 2, 9, 803-813 (2015)

6. B. B. Poter B.B., EPA Document, Method 415.3 (2009)

7. E. Laskawiec, M. Dudziak, J. Wyczarska-Kokot, Apar. Bad. Dydakt., 21, 238-245 (2016) 